\title{
Relationship between Collaboration in Work Support and Knowledge and Skills in Providing Support for Individuals with Disabilities
}

\author{
Kazuaki Maebara ${ }^{1, *}$ and Jun Yaeda ${ }^{2}$ \\ ${ }^{1}$ Department of Education and Human Studies, Akita University, Akita City, Japan \\ ${ }^{2}$ Graduate School of Comprehensive Human Studies, University of Tsukuba, Tokyo, Japan
}

\begin{abstract}
Background: There has been growing hope for initiatives supporting the transition of persons with disabilities from employment-related welfare services to employees in companies. This is against the backdrop of a significant increase in employment among persons with disabilities in Japan.

Objective: To improve the quality of this transition, this study examined the relationship between the collaboration of the Work Support Centers for Continuous Employment Type B (WSC-B) with vocational rehabilitation organizations (VROs) and knowledge and skills related to employment support.

Methods: A survey including all 122 WSC-B in L-Prefecture was conducted by postal mail. The respondents were asked to rate items on the following six levels concerning collaboration with VROs and understanding of VROs. We used the Japanese version of the Self-Assessment for Students or Counselors (SASC-J) to assess knowledge and skills related to work support.

Results: The t-test conducted on knowledge and skills status between WSC-B with a high degree of cooperation with VROs and those with low degrees confirmed significant differences among the various subsystems in VROs.

Conclusion: Based on our results, we suggest that maximizing the use of collaboration in work support will enhance the support provided by WSC-B and promote transition support for people with disabilities.
\end{abstract}

Keywords: Vocational rehabilitation, transition support, work support, SASC-J, competitive employment.

\section{INTRODUCTION}

In recent years, the number of job listings and the level of employment for persons with disabilities in Japan has been increasing significantly [1]. Against this backdrop, there are growing opportunities for persons with disabilities to transition from employment-related welfare services to employees in companies. According to the Comprehensive Support of Persons with Disabilities Act, one way to offer employment-related welfare support to persons with disabilities in Japan is through the Work Support Centers for Continuous Employment. This framework offers opportunities for employment and production to those who cannot be hired easily through competitive employment. To this end, there are initiatives for training to improve their knowledge and skills.

Work Support Centers for Continuous Employment are categorized into Work Support Centers for Continuous Employment Type A (WSC-A) and Work Support Centers for Continuous Employment Type B (WSC-B). WSC-A specializes in employing persons with disabilities by concluding employment contracts,

*Address correspondence to this author at 1-1, Tegata-Gakuenmachi, Akita, 010-8502, Japan; Tel/Fax: +8118-889-2548;

E-mail: maebara-kazuaki@ed.akita-u.ac.jp while WSC-B does not offer employment. Both the WSC-A and WSC-B can be used for an unlimited period. In addition, there are Work Transition Support Services (WTSS), which offer participation in the production of goods at institutions during a standard two-year period and provide training for people with disabilities to gain knowledge and develop skills required for working. WTSS are places of support for developing motivation to gain employment.

Between 2008 and 2017, the number of people with disabilities using employment-related welfare services increased by about 4.56 times [2]. Among them, those who transitioned to being employed in competitive employment increased by about 4.95 times during the same period. At the same time, however, transitions from WSC-A and WSC-B remained unchanged among employment-related welfare service centers for persons with disabilities.

Only $54.8 \%$ of the users at WSC-A and $80 \%$ at WSC-B made such transitions. In addition, there are many centers with no records of users transitioning to competitive employment in the first place, pointing to great disparities among centers. Improving the quality of transitions has become a fundamental issue in regions where there are few social resources or training for vocational support. 
Multi-organization collaboration is considered effective in achieving this goal because it enables comprehensive services to accommodate different standards and needs, which improves service quality for users [3]. However, this does not simply improve the quality of the support services provided. Nonaka, Takamuro, and Uehara referred to six targets for case meetings, which are specific methods for promoting collaboration. These are: (a) make comprehensive and appropriate decisions by engaging multiple people to be deliberate and reduce the burden placed on the assigned staff; (b) each participant learns and gains skills in categories new to them; (c) form networks among supporters through learning each other's roles and service functions; (d) foster affective support among participants in high-stress fields; (e) staff can learn from case studies; and (f) offer opportunities to learn specific local issues in relation to cases reviewed [4].

When applying these methods, collaboration improves the quality of support services and enhances the quality of the services provided in a particular region in the future. However, it must be noted that although collaboration appears simple, it is often difficult in practice. Nonetheless, as discussed above, significant benefits can be achieved through collaboration. Previous literature on work support has frequently confirmed the significance of collaboration. However, collaboration can also often be treated as a low priority in actual practice because of difficulties in implementation and communication. As a result, even if a support center replied that collaboration is in place, there are cases in which it has become obsolete. Quality improvement in work support is possible if the efficacy of collaboration is acknowledged among supporters and if it can be adequately practiced. To address this issue, this study investigates whether collaboration on work support contributes to improvements in knowledge and skills in the field.

\section{METHODS}

\section{Organizations Selected to Participate in the Study}

All 122 WSC-B (as of April 1, 2020) in L-Prefecture were contacted as study respondents. A survey questionnaire was sent to the respondents by mail. The front cover of the questionnaire assured respondents that their personal information would be protected and that it would not be used for purposes other than for this study. Informed consent was confirmed by returning the questionnaire.

\section{Study Period and Procedure}

This study was conducted between July 20 and August 31, 2020. Surveys were sent by mail, and the responses were sent back by the same delivery method.

\section{Survey Items}

The survey questionnaire is consists of five parts: basic information, support services provided to users with disabilities, assessment, collaboration with vocational rehabilitation organizations (VROs), and knowledge and skills related to working support.

Among the VROs, the study examined the status of collaboration among Local Vocational Centers for Persons with Disabilities (LVC), Employment and Livelihood Support Centers for Persons with Disabilities (ELSC), and Public Employment Security Offices (PESO). In addition, we analyzed how organizational roles are understood and the level of knowledge and skills related to work support.

\section{Collaboration with VROs}

Concerning collaboration with VROs, the respondents were asked to rate items on the following six levels: never heard of it or do not know (0 points), no collaboration at all (1 point), not much collaboration ( 2 points), neither ( 3 points), sometimes collaborate (4 points), and collaborate fully (5 points).

To understand VROs, the respondents were asked to rate items on the following six levels: never heard of it or do not know (0 points), no knowledge at all (1 point), not much knowledge (2 points), neither (3 points), some knowledge (4 points), and full knowledge (5 points).

\section{The Japanese Version of the Self-Assessment for Students or Counselors}

Concerning knowledge and skills related to work support, we used the Japanese version of the SelfAssessment for Students or Counselors (SASC-J) [5]. This comprises 80 items to self-assess the knowledge and skills of students studying vocational rehabilitation and workers in actual practice.

There are eight subsystems in the instrument: the client (15 items), health (8 items), education (6 items), family (5 items), social (12 items), employee (14 items), placement (10 items), and funding (12 items) subsystems. 
Kundu et al. created the original English version of the SASC-J, with the details and suitability of the items verified [6]. The SASC-J is a translation using the backtranslation method of the English version. In this study, an assessment was made of knowledge and skills related to work support. Each item was scored on five levels: I have no knowledge or skill (1 point); I have minimum knowledge or skill (2 points); I have average knowledge or skill (3 points); I have more than average knowledge or skill (4 points); I have enough knowledge or skill to train someone (5 points).

The contents of this SASC-J are shown in the Supplementary Material.

\section{Analysis Method}

We made a simple tabulation of the items on collaboration and understanding. We also conducted a Pearson correlation analysis.

We then classified the respondents into two groups: high (4 and 5) and low (0 to 3 ) in terms of the status of collaboration with and understanding of VROs. We also performed a t-test on the differences among the average scores in each group.

\section{RESULTS}

\section{Response Rate}

There were 65 valid responses, a response rate of $53.3 \%$ among all 122 WSC-B in the L-Prefecture.

\section{Collaboration with and Understanding of VROs}

Table 1 shows the scores obtained regarding collaboration with and understanding of VROs. In terms of collaboration, ELSC was highest at 3.49 , followed by PESO at 2.72, and LVC at 2.17. Concerning the level of understanding, PESO was the highest at 4.34 , followed by ELSC at 4.26 and LVC at 3.45. We ran a Pearson correlation analysis for each VRO's current collaboration and understanding level. The results showed significant relationships: LVC was $r=0.409$ ( $p$ $<0.01)$, ELSC was $r=0.538(p<0.01)$, and PESO was $r$ $=0.261(p<0.01)$.

\section{Knowledge and Skills Related to Employment Support}

Table 2 shows the knowledge and skills related to employment support, as determined by the SASC-J. The client and family subsystems were highest at 3.1, and the education subsystem was lowest at 2.1 .

Table 1: Collaboration with and understanding of VROs.

\begin{tabular}{|c|c|c|c|}
\hline Vocational rehabilitation organization & Setting & Mean & Standard deviation \\
\hline \multirow{2}{*}{ LVC } & Collaboration & 2.17 & 1.23 \\
\hline & Understanding & 3.45 & 1.08 \\
\hline \multirow{2}{*}{ ELSC } & Collaboration & 3.49 & 1.23 \\
\hline & Understanding & 4.26 & 0.80 \\
\hline \multirow{2}{*}{ PESO } & Collaboration & 2.72 & 1.28 \\
\hline & Understanding & 4.34 & 0.76 \\
\hline
\end{tabular}

LVC: Local Vocational Centers for Persons with Disabilities.

ELSC: Employment and Livelihood Support Centers for Persons with Disabilities.

PESO: Public Employment Security Offices.

Table 2: Possession of Knowledge and Skills Related to Employment Support

\begin{tabular}{|c|c|c|c|c|}
\hline Subsystem & Mean & Standard deviation & Minimum & Maximum \\
\hline \hline Client & 3.1 & 0.62 & 1.73 & 1.00 \\
\hline Education & 2.1 & 0.87 & 1.00 & 4.00 \\
\hline Health & 2.9 & 0.84 & 1.20 & 5.00 \\
\hline Family & 3.1 & 0.85 & 1.00 & 5.00 \\
\hline Social & 2.4 & 0.74 & 1.00 & 3.80 \\
\hline Employer & 2.4 & 0.93 & 1.00 & 5.00 \\
\hline Placement & 2.5 & 0.89 & 1.00 & 5.00 \\
\hline Funding & 2.8 & 0.78 & & 4.58 \\
\hline
\end{tabular}


Table 3: Number of Organizations that Responded on Items Regarding Collaboration and Comprehension Level

\begin{tabular}{|l|c|c|c|}
\hline \multicolumn{2}{|c|}{ Support organization } & Collaboration (\%) & $36(55.4)$ \\
\hline \hline \multirow{2}{*}{ LVC } & High & $15(23.0)$ & $29(44.6)$ \\
\cline { 2 - 4 } & Low & $50(77.0)$ & $59(90.8)$ \\
\hline \multirow{2}{*}{ ELSC } & High & $42(64.6)$ & $6(9.2)$ \\
\cline { 2 - 4 } & Low & $23(35.4)$ & $58(89.2)$ \\
\hline \multirow{2}{*}{ PESO } & High & $23(35.4)$ & $7(10.8)$ \\
\cline { 2 - 4 } & Low & $42(64.6)$ & \\
\hline
\end{tabular}

LVC: Local Vocational Centers for Persons with Disabilities.

ELSC: Employment and Livelihood Support Centers for Persons with Disabilities.

PESO: Public Employment Security Offices.

\section{Difference in Knowledge and Skills Attributable to Low and High Scores in the Level of Collaboration}

Table 3 shows the results for the number of organizations that responded to items regarding collaboration and understanding levels. Concerning current collaborations, many LVCs and PESOs scored low, while ELSCs scored high. In addition, many organizations had high scores in terms of understanding. We performed a t-test on the average scores for each category of knowledge and skills among groups per VRO to understand collaboration status. In the t-test performed on knowledge and skills status between WSC-B establishments with a high degree of cooperation with VROs and those with a low degree of cooperation, significant differences were confirmed in the client, education, social, employee, placement, and funding of LVC, and the client, education, health, and funding of PESO.

Table 4 presents the results of this analysis.
We conducted a t-test on the average scores for each category of knowledge and skills among groups per support organization concerning comprehension level; the results are presented in Table 5 . From the ttest we conducted on the knowledge and skills status of WSC-B with a high level of understanding of VROs and those with a low level of understanding, significant differences were confirmed in the client, employment, and funding of the LVC.

\section{DISCUSSION}

In Japan, the number of users of employmentrelated welfare services for persons with disabilities is about 375,000 [2]. In 2019, about 20,000 people transitioned from employment-related welfare services for persons with disabilities to company employment; this number is increasing every year [2]. In 2020, Japan's Ministry of Health, Labour and Welfare (MHLW) held its first conference to discuss strategies for collaboration between employment-related disability

Table 4: Difference of Knowledge and Skills According to the Status of Collaboration

\begin{tabular}{|c|c|c|c|c|c|c|c|c|c|}
\hline \multirow{2}{*}{ Subsystem } & \multicolumn{3}{|c|}{ LVC } & \multicolumn{3}{|c|}{ ELSC } & \multicolumn{3}{|c|}{ PESO } \\
\hline & High & Low & p-Value & High & Low & p-Value & High & Low & $p$-Value \\
\hline Client & 3.4 & 2.9 & $* *$ & 3.1 & 3.0 & n.s. & 3.4 & 2.9 & $* *$ \\
\hline Education & 2.6 & 1.9 & $* *$ & 2.0 & 2.2 & n.s. & 2.4 & 1.9 & $*$ \\
\hline Health & 3.2 & 2.8 & n.s. & 2.9 & 2.7 & n.s. & 3.2 & 2.7 & $*$ \\
\hline Family & 3.4 & 3.0 & n.s. & 3.2 & 3.0 & n.s. & 3.4 & 3.0 & n.s. \\
\hline Social & 2.9 & 2.2 & $* *$ & 2.3 & 2.5 & n.s. & 2.5 & 2.4 & n.s. \\
\hline Employer & 3.0 & 2.3 & $* *$ & 2.4 & 2.6 & n.s. & 2.7 & 2.3 & n.s. \\
\hline Placement & 3.0 & 2.3 & $* *$ & 2.4 & 2.6 & n.s. & 2.7 & 2.3 & n.s. \\
\hline Funding & 3.3 & 2.6 & $* *$ & 2.8 & 2.9 & n.s. & 3.1 & 2.6 & $*$ \\
\hline
\end{tabular}

${ }^{*} p<.05 * * p<.01$

LVC: Local Vocational Centers for Persons with Disabilities.

ELSC: Employment and Livelihood Support Centers for Persons with Disabilities.

PESO: Public Employment Security Offices. 
Table 5: Difference of Knowledge and Skills According to Comprehension Level

\begin{tabular}{|c|c|c|c|c|c|c|c|c|c|}
\hline \multirow{2}{*}{ Subsystem } & \multicolumn{4}{|c|}{ LVC } & \multicolumn{3}{c|}{ ELSC } & \multicolumn{3}{c|}{ PESO } \\
\cline { 2 - 17 } & High & Low & $\boldsymbol{p}$-Value & High & Low & p-Value & High & Low & p-Value \\
\hline \hline Client & $\mathbf{3 . 2}$ & 2.8 & $*$ & 3.1 & 3.0 & n.s. & 3.1 & 2.6 & n.s. \\
\hline Education & 2.3 & 1.8 & n.s. & 2.1 & 2.3 & n.s. & 2.1 & 1.8 & n.s. \\
\hline Health & 3.0 & 2.7 & n.s. & 2.9 & 2.8 & n.s. & 2.9 & 2.4 & n.s. \\
\hline Family & 3.1 & 3.1 & n.s. & 3.1 & 3.6 & n.s. & 3.1 & 3.0 & n.s. \\
\hline Social & 2.6 & 2.2 & n.s. & 2.4 & 2.8 & n.s. & 2.4 & 2.5 & n.s. \\
\hline Employer & $\mathbf{2 . 7}$ & 2.2 & $*$ & 2.4 & 3.2 & n.s. & 2.4 & 2.5 & n.s. \\
\hline Placement & 2.6 & 2.3 & n.s. & 2.4 & 2.8 & n.s. & 2.5 & 2.1 & n.s. \\
\hline Funding & $\mathbf{3 . 0}$ & 2.5 & $* *$ & 2.7 & 3.2 & n.s. & 2.8 & 2.5 & n.s. \\
\hline
\end{tabular}

${ }^{*} p<.05{ }^{* *} p<.01$.

LVC: Local Vocational Centers for Persons with Disabilities.

ELSC: Employment and Livelihood Support Centers for Persons with Disabilities.

PESO: Public Employment Security Offices.

welfare services and vocational rehabilitation to promote employment of people with disabilities [7]. This government activity increased efforts further to intensify the general employment of people with disabilities and improve the quality of employment support, attracting attention in Japan.

Collaboration with VROs is important for the transition to company employees. In Japan, LVCs play a significant role in workplace retention support, as represented by job coach support; ELSCs provide employment support and long-term follow-up support; and PESOs implement procedures related to job placement and subsidy utilization. This service system of vocational rehabilitation in Japan is explained in detail by Boeltzig-Brown [8].

The National Institute of Vocational Rehabilitation (NIVR) in Japan reports that multi-agency collaboration, including these VROs, increases the length of time people with disabilities are retained in the workplace [9]. The collaboration will contribute to the retention of individual users in the workplace. It will also contribute to improving the knowledge and skills of the staff of WSC-B regarding employment support. This improvement in knowledge and skills can be attributed to the fact that the LVCs that create a vocational rehabilitation plan provide companionship to local support organizations. A report on the practice of vocational rehabilitation counselors for persons with disabilities at the LVCs makes the following points. In collaboration, timely communication between supporters is necessary [10], and cooperation among supporters, consistent feedback, and sharing of the support process are important [11]. It is necessary to develop a common understanding and share information to maintain collaboration [12]. Thus, the practice of LVCs shows that we are aware of the support we can provide to institutions through collaboration.

It has already been shown that there is a lack of knowledge and skills regarding vocational rehabilitation among work supporters in Japan. Yaeda et al. reported a lack of knowledge and skills in a survey of job coaches in the SASC-J, which was also used in this study [5]. Fujii and Yaeda showed that employment supporters' perception of their own expertise was influenced by their experience of attending training related to vocational rehabilitation [13]. However, practically there is no adequate training system for work supporters in Japan [14].

Maebara and Nawaoka [15] pointed out that one of the issues that work support needs to solve in the future is the training of highly specialized work supporters in higher education institutions and the promotion of research on vocational rehabilitation in higher education institutions. Of course, there is a possible need for such systematic training and education systems. However, the results of this study showed more than just the necessity of a system, but the fact that welfare agencies do not have any contact with VROs, which should be established in a normal scheme. In other words, the issue here is that welfare agencies do not have basic information about work support and do not have access to it. This issue can be improved with a little ingenuity in daily practice. We need to create an environment in which work supporters can devise ways to improve this situation. 
It is said that collaboration allows for the comprehensive provision of services of various levels and dimensions, thus enhancing the quality of services provided to users [3]. However, since it is said that it is a myth that collaboration will work if experts simply get together [16], collaboration is difficult even though it seems to be easy. In addition, Fukuyama points out that collaboration is often misunderstood as aligning views, opinions, and goals or agreeing with opinions expressed by other professionals [17]. Rather, it is important to reconsider the nature of collaboration from the perspective that an expert cannot do everything by himself, but someone who can only do what he specializes in and can achieve explosive performance when collaborating with other experts [18]. From this stance, it is necessary to aim for constructive collaboration that maximizes the performance of each supporter within the realistic constraints of solving the "difficulties in working" [19] of the persons to be supported. This will result in good outcomes of the support because of the collaboration and enable the work supporters to gain a lot of knowledge and skills that will help them create the next support from this support.

Unlike the WTSS, which focuses on the intention to work for a company within a two-year user period, WSC-B does not have a maximum period of use for users, and the number of users who transition to work in a company is small. Therefore, in the current situation, there is inadequate support for collaboration with VROs and competitive employment. Therefore, to further improve the self-determination and quality of life of those who wish to use the service, it will be necessary to collaborate with them to transition to competitive employment actively. Collaboration with VROs such as LVCs improves the quality of support from users without WSC-B to implement support in transitioning to the next competitive employment.

\section{CONCLUSION}

This research is based on data collected from LPrefecture, which is a limited region. This prefecture is located in a rural region of Japan and has few social resources for work support for people with disabilities. Some types of benefits are expected from the perspective of collaboration. However, there is a regional disparity in the number of local social resources. It is necessary to conduct further studies considering these limitations.

We can assume that the conditions differ, such as involvement with VROs. Therefore, there is a need for future studies covering a wide range of regions to obtain further evidence to support the research results.

\section{ETHICAL CONSIDERATIONS}

This study was approved by the Research Ethics Screening Committee for recruiting research participants in the Tegata Region of Akita University (No. 2-3 on May 22, 2020).

\section{ACKNOWLEDGEMENT}

We thank everyone at WSC-B who supported us in this study. We thank everyone who collaborated in conducting this research and their great support. We would like to thank Editage (www.editage.com) for English language editing.

\section{FUNDING}

This work was supported by the Ministry of Health, Labour and Welfare in Japan under Grant number $20 G C 1001$.

\section{CONFLICT OF INTEREST}

The authors reported no potential conflict of interest.

\section{SUPPLEMENTAL MATERIALS}

The supplemental materials can be downloaded from the journal website along with the article.

\section{REFERENCES}

[1] Ministry of Health, Labour and Welfare [Internet] Employment placement status of persons with disabilities in 2019 [cited 2020 June 23]; (In Japanese). Available from: https://www.mhlw.go.jp/content/11704000/000641906.pdf

[2] Ministry of Health, Labour and Welfare [Internet]. Current situation of employment support measures for persons with disabilities; [Cited 2019 December 31]; (In Japanese). Available from: https://www.mhlw.go.jp/stf/seisakunitsuite/ bunya/hukushi_kaigo/shougaishahukushi/service/shurou.htm I

[3] Harley DA, Donnell C, Rainey JA. Interagency collaboration: Reinforcing professional bridges to serve aging populations with multiple service needs. J Rehab 2003; 69(2): 32-37.

[4] Nonaka T, Takamuro N, Uehara H. Techniques for care conference. Tokyo: Chu-oh-Houki Publishing 2007; (In Japanese).

[5] Yaeda J, Kundu M, Nishimura S. Self-perceived knowledge and skills of job coaches in Japan. Work 2013; 45(2): 279285.

[6] Kundu M, Geist CS, Dutta A. A systems approach to placement: A holistic technique. J For Vocat Anal 2005; 8: 21-30.

[7] Ministry of Health, Labour and Welfare [Internet]. Committee on Strengthening Collaboration between Employment and Welfare Policies for the person with disabilities [cited 2021 October 6]; (In Japanese). Available from: https://www.mhlw.go.jp/stf/newpage_14599.html 
[8] Boeltzig-Brown H, Sashida C, Nagase O, Kiernan WE, Foley $\mathrm{SM}$. The vocational rehabilitation service system in Japan. J Vocat Rehabil 2013; 38: 169-183. https://doi.org/10.3233/JVR-130632

[9] The National Institute of Vocational Rehabilitation. Research on employment status of persons with disabilities. Research Reports, 2017; 137. (In Japanese). [cited 2021 October 6]. Available from: https://www.nivr.jeed.go.jp/research/report/ houkoku/houkoku137.html

[10] Kitaguchi $Y$. What is required of supporters to continue working at a company? A case study of local vocational centers for persons with disabilities user. The 19th National Conference of Vocational Rehabilitation Research and Practice; 2011: Chiba City, Chiba Prefecture, Japan: Japan Organization for Employment of the Elderly, Persons with Disabilities and Job Seekers 2011; pp. 115-118 (In Japanese).

[11] Araki K, Ota K, Hidaka Y, Haga M. A study on the collaboration between public employment security offices and local vocational Centers for Persons with Disabilities: A case study of the total supporter training for employment of persons with psychiatric disabilities and its application to employment. The 20th National Conference of Vocational Rehabilitation Research and Practice; 2012: Chiba City, Chiba Prefecture, Japan: Japan Organization for Employment of the Elderly, Persons with Disabilities and Job Seekers 2012; pp. 211-214 (In Japanese).

[12] Murakuki $Y$, Toyokawa M, Suzuki O, Mizuno M, Iwakura $\mathrm{H}$, Teramoto K. A study on support for business owners launching new. Business, 1 -. Initiatives to support the launch of new businesses by the special subsidiary company through collaboration among regional employment support organizations. The 19th National Conference of Vocational Rehabilitation Research and Practice; 2011: Chiba City, Chiba Prefecture, Japan: Japan Organization for Employment of the Elderly, Persons with Disabilities and Job Seekers 2011; pp. 226-229 (In Japanese).

[13] Fuji A, Yaeda J. Study of Influence factor with competencies of vocational rehabilitation counselor. Research Bulletin 2017; 67: 1-8 (In Japanese).

[14] Matsui N. Considerations in the promoting of the supporter's talent for the employment of persons with disabilities. The monthly journal of the Japan Institute of Labour 2013; 55(10): 54-62 (In Japanese).

[15] Maebara K, Nawaoka K. A clarification of key discussion points for promoting the implementation of vocational assessment in employment-related disability welfare service agencies. General Human Science 2021; 7: 35-52.

[16] Bowen WT, Marler DC, Androse L. The psychiatric team: Myth and Mystique. Am J Psychiatry 1965; 122: 687-690. https://doi.org/10.1176/ajp.122.6.687

[17] Fukuyama K. Cooperative techniques in social work. Studies on Social Work2009; 34(4): 278-290 (In Japanese).

[18] Uchida T. Theories of education discussed in the streets. Tokyo: Mi-shi-ma-sha Publishing 2008; (In Japanese)

[19] Aizawa K. Basics of support in vocational rehabilitation. In: Japan Society for Vocational Rehabilitation, editors. Fundamentals and practices of vocational rehabilitation. Tokyo: Chu-o-ho-ki Publishing 2012; pp. 92-123.

Received on 24-08-2021

Published on 08-12-2021

https://doi.org/10.6000/2292-2598.2021.09.06.2

(c) 2021 Maebara and Yaeda; Licensee Lifescience Global.

This is an open access article licensed under the terms of the Creative Commons Attribution License (http://creativecommons.org/licenses/by/4.0/) which permits unrestricted use, distribution and reproduction in any medium, provided the work is properly cited. 